\title{
UM ESTUDO SOBRE O EMPREENDEDORISMO INCENTIVADO POR POLÍTICAS PÚBLICAS DE ASSISTÊNCIA SOCIAL NO MUNICÍPIO DO RIO DE JANEIRO
}

\section{A STUDY ON ENTREPRENEURSHIP ENCOURAGED BY PUBLIC POLICIES OF SOCIAL ASSISTANCE IN THE MUNICIPALITY OF RIO DE JANEIRO}

Irene Dobarrio Machado Ciccarino

ireneciccarino@phd.iag.puc-rio.br

Recebido em 29.12.2017. Aprovado em 29.04.2018 Avaliado pelo sistema double blind review

Pontifícia Universidade Católica do Rio de Janeiro (IAG/PUC-Rio) - Rio de Janeiro - RJ

\section{Allan Borges}

allanborgesri@yahoo.com.br

Fundação Getúlio Vargas (FGV - CPDOC) - Rio de Janeiro - RJ

Daniely Silva de Viveiros

danielyviveiros@hotmail.com

Universidade Estadual do Rio de Janeiro (UERJ - PPGPPFH) - Rio de Janeiro - RJ

\section{Resumo}

Esta pesquisa identifica de que maneira o empreendedorismo pode colaborar com o público usuário das políticas públicas de assistência social no município do Rio de Janeiro. Apresenta o empreendedorismo como elemento de mudança de trajetórias de vida por meio do desenvolvimento da autonomia, a partir de estímulos as potências dos indivíduos e suas famílias. Trata-se de um estudo comparativo baseado na reaplicação do modelo de regressão linear anteriormente desenvolvido com uma amostra dos beneficiários do programa Minha Casa, Minha Vida no mesmo município. O questionário foi reaplicado com os beneficiários vinculados aos Centros de Referência de Assistência Social que permitiu analisar a variação entre amostras de uma mesma população, além de investigar a confiabilidade do modelo, a relevância de seus achados e a capacidade de generalização de suas conclusões. Espera-se, com isso, promover uma discussão sobre as principais questões que geram a necessidade de atendimento desse público e uma melhor compreensão sobre as variáveis que compõem o perfil desse empreendedor, de modo que seja possível avaliar a pertinência da promoção de ações que estimulem o empreendedorismo. A partir do questionamento sobre como o empreendedorismo pode colaborar com o desenvolvimento social, chegamos às duas hipóteses: $\mathrm{H} 1$ : $\mathrm{O}$ público alvo das políticas públicas de assistência social apresenta perfil empreendedor; H2: Características que dificultam o acesso ao mercado de trabalho são menos relevantes para o desenvolvimento de atividade empreendedora. Foram aplicados 293 questionários, considerando amostragem probabilística com pessoas que acessaram esses serviços na data de aplicação dos questionários e se voluntariaram a participar. Para permitir as generalizações, combinou-se a literatura de empreendedorismo com a discussão de construtos que permeiam à assistência social. Concluiu-se que 0 empreendedorismo pode ser uma alternativa válida para ajudar a superar limitações decorrentes da desigualdade social, desenvolvendo autonomia e gerando emprego e renda a partir do território.

Palavras-chaves: Empreendedorismo. Políticas Públicas. Perfil Empreendedor. Assistência Social. Análise Multivariada. 


\section{Abstract}

This research identifies how entrepreneurship can collaborate with the public policies of social assistance in the municipality of Rio de Janeiro. It presents entrepreneurship as an element of change in life trajectories through the development of autonomy, from stimuli to the powers of individuals and their families. This is a comparative study based on the reapplication of the linear regression model previously developed with a sample of the beneficiaries of the "Minha Casa, Minha Vida" program in the same municipality. The questionnaire was reapplied with the beneficiaries linked to the Social Assistance Reference Centers [CRAS and CREAS], which allowed to analyze the variation among samples of the same population, as well as to investigate the reliability of the model, the relevance of its findings and the generalization capacity of its conclusions. It is hoped, therefore, to promote a discussion about the main issues that generate the need of attendance of this public and a better understanding about the variables that make up the profile of this entrepreneur, so that it is possible to evaluate the pertinence of the promotion of actions that stimulate entrepreneurship. From the questioning about how entrepreneurship can collaborate with social development, we come to the two hypotheses: $\mathrm{H} 1$ : The target audience of the public policies of social assistance presents an entrepreneurial profile; $\mathrm{H} 2$ : Characteristics that hinder access to the labor market are less relevant for the development of entrepreneurial activity. A total of 293 questionnaires were applied, considering probabilistic sampling with people who accessed these services on the date of application of the questionnaires and volunteered to participate. To allow for generalizations, the entrepreneurship literature was combined with the discussion of constructs that permeate social assistance. It was concluded that entrepreneurship can be a valid alternative to help overcome limitations resulting from social inequality, developing autonomy and generating employment and income from the territory.

Keywords: Entrepreneurship; Public policy; Profile Entrepreneur; Social assistance; Multivariate analysis.

\section{Introdução}

Para estimular a reflexão sobre o perfil do público atendido pelas políticas públicas de assistência social no município do Rio de Janeiro, partimos da premissa que a administração estuda "(...) a melhor maneira por meio da qual as organizações definem e alcançam objetivos. Sem ela, a civilização moderna e seus processos de criação de riqueza não poderiam sequer existir. " Como uma ciência social aplicada, pode contribuir com a definição e alcance de metas no âmbito social, e seus conceitos podem ser democratizados para que os mais variados agentes se beneficiem de seus princípios de planejamento, organização, direção e controle. Sob esta perspectiva, o empreendedorismo foi selecionado como vinculação teórica que norteou as análises dessa colaboração no desenvolvimento social (CHIAVENATO, 2013).

Este estudo busca identificar como o empreendedorismo pode colaborar com o rompimento de ciclos de reprodução da desigualdade por meio do exercício da autonomia como elemento de mudança para conquista da emancipação pessoal e social. Ele baseia-se na análise estatística de dados, comparando 0 modelo de regressão linear anteriormente desenvolvido com uma amostra dos beneficiários do programa Minha Casa, Minha Vida no município do Rio de Janeiro. Foi reaplicado o mesmo questionário com os beneficiários do sistema de assistência social vinculados aos Centros de Referência de Assistência Social [CRAS] e Centros de Referência Especializado de Assistência Social [CREAS], no mesmo município. Os CRAS fornecem atendimento à população em geral de acordo com a referência territorial do bairro de residência e os CREAS são voltados ao atendimento de caso de vulnerabilidade ou risco social e violação de direitos (Brasil MDS, 2005). Esses dispositivos públicos estão presentes em todo Brasil, fazendo parte de uma política de universalização de direitos sociais no Sistema Único de Assistência Social [SUAS].

A comparação entre modelos permite analisar a variação entre amostras de uma mesma população beneficiários de políticas de assistência social -, permitindo investigar a confiabilidade do modelo, a relevância de seus achados e a capacidade de generalização de suas conclusões. 
O principal objetivo deste estudo é caracterizar o público atendido por essas políticas de assistência social, identificando seu perfil empreendedor. Espera-se, com isso, promover uma discussão sobre as principais questões que geram essa necessidade de atendimento e sobre como o empreendedorismo pode ajudar a superá-las, de modo que seja possível avaliar a pertinência do investimento em ações de incentivo ao empreendedorismo.

A relevância desse estudo está na intersetorialidade dos temas envolvidos, agregando riqueza à formulação teórica em ambas as áreas, a saber: Administração e Serviço Social. Além disso, o teste empírico sobre 0 perfil empreendedor dos beneficiários das políticas de assistência social, agrega informações sobre esse público por um viés pouco usual, além de complementar a temática de perfil empreendedor ao utilizar elementos da literatura de empreendedorismo e dados do Global Entrepreneurship Monitor [GEM], um dos maiores repositórios de dados sobre esse tema.

A partir do questionamento sobre como o empreendedorismo pode colaborar com o desenvolvimento social quando estimulado junto ao público atendido por essas políticas, chegamos a duas hipóteses: $\mathrm{H}$ 1: $\mathrm{O}$ público alvo das políticas públicas de assistência social apresenta perfil empreendedor; $\mathrm{H} 2$ : Características que dificultam o acesso ao mercado de trabalho são menos relevantes para o desenvolvimento de atividade empreendedora. Essas hipóteses foram testadas estatisticamente por meio de Regressão Linear e Análise de Cluster.

Convém mencionar que, embora não seja o enfoque deste estudo, a observação dessas hipóteses geraram ações afirmativas no âmbito das Políticas Públicas de Assistência Social na cidade do Rio de Janeiro. Aqui nos concentraremos na análise e apresentação dos dados coletados ao longo da execução desses projetos.

\section{Fundamentação Teórica}

\section{A Política Nacional de Assistência social}

A experiência na gestão da política pública de assistência social traz à tona questões relevantes para o enfrentamento das situações de pobreza e de acesso aos direitos sociais. A partir de 2004, com o marco de implantação da Política Nacional de Assistência Social, vários aspectos foram incorporados às estratégias de gestão, circunscritos no aparato estatal enquanto esfera de planejamento e execução de programas e serviços de atendimento (BRASIL MDS, 2005).

Dentre estes aspectos, está a perspectiva de respostas às necessidades humanas de forma integral, de maneira preventiva e protetiva. A autonomia é um dos conceitos apontados e utilizados como base na execução dos serviços. A autonomia pode ser traduzida no processo que constitui a capacidade dos sujeitos de "compreenderem e agirem sobre si mesmos e sobre o contexto, conforme objetivos democraticamente estabelecidos" (BRASIL, 2013, p. 69). Nesta perspectiva, o empreendedorismo desponta enquanto um novo olhar sobre a identificação e delimitação de recursos, de modo a transformá-los em oportunidades. 0 acesso aos serviços públicos aliado às estratégias de inclusão produtiva busca superar a situação de pobreza, tendo como pano de fundo a ação combinada de diferentes agentes sociais - gestores, executores e público usuário.

Historicamente, na política de assistência social, a renda é um indicador de seleção de beneficiários de programas sociais. Entretanto, as ações de atendimento vêm sendo redesenhadas, incorporando mecanismos prioritários, como acessos aos serviços públicos e inserção produtiva, de forma a fomentar 0 alcance de famílias e indivíduos extremamente pobres, mas dentro de um enfoque multidimensional de pobreza. Santana $(2016$, p. 6$)$ indica que:

O conceito de pobreza não é estático, [...] As tentativas de conceituar a pobreza devem, portanto, considerar o seu contexto social, histórico, econômico e cultural. Suas análises buscam superar a simples relação entre causa e efeito, deve-se considerar a sua multidimensionalidade e seu caráter multifacetado, através de variáveis como segregação e heterogeneidade de formas de ocupação do território. Da mesma forma, a superação da 
pobreza e das desigualdades requer uma gama de ações e políticas igualmente complexas.

Buscando uma visão de gestão capaz de ações integradas e integradoras, de investimento em novas trajetórias, o que, consequentemente, tira a política pública do seu voluntarismo e de seus determinismos socioculturais, que em conteúdo é explicado como "má fé institucional" (SOUZA, 2009). Essa má fé ocorre quando partimos de premissas privilegiadas para pautar as necessidades de um público mais vulnerável, que percorreu outras trajetórias por meio de acessos (ou a falta deles) diferentes. Desse modo, a oferta não sensibiliza o beneficiário a uma mudança efetiva, não se adequando a sua capacidade de perceber e aproveitar oportunidades, o que gera frustrações de ambos os lados.

\section{A Secretaria Municipal de Desenvolvimento Social - SMDS}

A Secretaria Municipal de Desenvolvimento Social [SMDS], entre os anos de 2013 e 2016, foi o organismo responsável por proteger crianças e adolescentes em situação de risco social, incluir famílias vulneráveis em programas de transferência de renda e acompanhá-las em seu percurso social, tratar da problemática da população em situação de rua, ou seja, foi uma secretaria que lidou diariamente com violações de direitos (BRASIL, 2014).

Os serviços, projetos, programas e benefícios socioassistenciais têm como foco prioritário a atenção às famílias e seus membros. Os territórios são as bases de organização, que passam a ser definidos pelas funções que desempenham, pelo número de pessoas que deles necessitam e pela sua complexidade. 0 principal desafio em contato com o beneficiário final era construir um processo de cocriação, incorporando novos elementos ao Sistema Único de Assistência Social [SUAS], proporcionando o aumento dos níveis de repertório social da política pública ofertada, mas, principalmente, ampliando a partir do conceito adotado por Velho (2013), o "campo de possibilidades como dimensão sócio cultural, espaço para formulação e implementação de projetos" das famílias atendidas nos CRAS E CREAS.

\section{O porquê do Empreendedorismo}

A desigualdade da distribuição de renda é negativamente relacionada ao nível de industrialização, pois restringe 0 tamanho do mercado. Embora haja a necessidade de uma classe média que sustente 0 crescimento da economia (CHOWDHURY, 2013), a maior parte da população mundial vive em condições de pobreza, dividindo $1 \%$ do total da riqueza concentrada no mundo, quanto os $1 \%$ mais ricos detém $99 \%$ dessa concentração. Quanto mais desigual é a sociedade, menos a economia cresce em longo prazo (PIKETTY, 2015; STIGLITZ, 2012).

A maioria das políticas públicas voltadas para o crescimento econômico apresentam três enfoques: 1) atração de novos negócios para a localidade; 2) encorajamento da criação de startups (negócios de rápido crescimento, em geral no campo da inovação e tecnologia); 3) promoção da expansão e estabilidade dos negócios existentes. A atração de novos negócios é limitada aos atrativos locais, o encorajamento à criação de startups é altamente arriscado e dependente de um ecossistema de inovação e tecnologia que o suporte. Por fim, existe a concentração de incentivos nas empresas que já apresentam algum tipo de crescimento e geram empregos, porém, esse perfil de empresa é o mais raro (SUMMERS, 2015). Devido a representatividade das pequenas empresas e trabalhadores autônomos nas economias, aos poucos as políticas públicas começam a se direcionar para o financiamento dessas atividades; (HERRINGTON; KEW, 2016). Porém, as rendas provenientes dessas atividades estão longe de serem satisfatórias para gerar alguma mudança no contexto de desigualdade e impactar com materialidade o crescimento da economia (SUMMERS, 2015). Com isso, retornamos ao efeito negativo da desigualdade social em um crescimento econômico sustentável.

A desigualdade social também gera os fatores que precisam ser mitigados pelas políticas de assistência social para conferir universalidade de direitos e buscar a criação de um estado de bem-estar social (ALABARCE, 2015).

Na literatura de empreendedorismo a abordagem que trata de populações menos favorecidas é a discutida 
por Prahalad (2006) sob o termo Base da Pirâmide para designar os $80 \%$ da população mundial que vivem com menos de dois dólares e cinquenta centavos por dia. De acordo com Prahalad (2006), existe um potencial enorme nesse mercado que apresenta demanda reprimida de bens e serviços. No entanto, para acessá-lo, é necessário baratear os custos a um ponto que a comercialização seja viável. Muitas empresas tentaram e ainda tentam explorar esse mercado, falhando em endereçar suas necessidades de uma forma sustentável (KARNANI, 2007). Aos poucos, um novo tipo de empreendedorismo começa a ganhar popularidade no intuito de prover essas populações - o empreendedorismo social - com empresas que utilizam seu resultado econômico para potencializar o resultado social de seu propósito, porém, esse campo ainda carece de amadurecimento teórico (DACIN et al, 2010).

Embora a política acabe priorizando o alívio da pobreza e suas externalidades, logo, atendendo uma parcela com recorte de renda inferior, cabe esclarecer que as pessoas atendidas pelo sistema de assistência social não necessariamente estão em situação tão precária para se classificarem como base da pirâmide, pois essa política é universal no Brasil, extensiva a qualquer cidadão. A pobreza ainda é tratada como uma questão isolada, como um efeito e não como uma questão estrutural que precisa ser socialmente endereçada devido a representatividade de seus números (SOARES, 2017).

De qualquer modo, a atividade empreendedora envolve riscos e altas taxas de mortalidade (HAYWARD et al, 2006). Segundo o SEBRAE (2017), a taxa de mortalidade dos novos negócios (empresas com até dois anos de idade) no Brasil é $23,4 \%$. O impacto real da atividade empreendedora é questionável tanto na sua amplitude quanto na sua sustentabilidade (SUMMERS, 2015). Se considerarmos a possível motivação empreendedora do público considerado nessa amostra, possivelmente ela se enquadraria na classificação de empreendedorismo por necessidade. Ela ocorre quando o empreendedor encontra dificuldades em se posicionar no mercado pelos mais diversos motivos, e empreende na esperança de obter retornos mais interessantes. Na maioria dos casos resulta em empresas pequenas e com baixo potencial de geração de empregos (HERRINGTON; KEW, 2016).

Parece pouco frutífero propor o incentivo ao empreendedorismo. Talvez, por isso, sua utilização como uma política de emancipação das classes mais baixas da sociedade seja pouco considerada. Porém, uma série de fatores empurram essas pessoas para o empreendedorismo sob a forma de trabalho informal ou subempregos (STIGLITZ, 2012; SUMMERS, 2015; SOARES, 2017). Talvez o que falte seja conhecimento sobre a capacidade dessas pessoas de serem os protagonistas de sua jornada econômica, além de informação, formação e estímulo para que o perfil empreendedor se transforme em uma atitude empreendedora e comece a gerar emprego e renda a partir do território. Não com a expectativa de gerar um enorme impacto econômico, mas na perspectiva da redução do custo com iniciativas de alívio da pobreza à medida que a geração de renda promove autonomia. $O$ objetivo, também, não é reduzir o investimento social, mas propor alternativas, aumentando o ganho social a partir desses investimentos.

Conforme Baron e Shane (2006), o empreendedorismo é um processo onde uma ideia é colocada em prática tornando-se um negócio economicamente viável e lucrativo. Esse processo ocorre por meio da identificação, avaliação e exploração de oportunidades. Por esse mecanismo a sociedade converte informação técnica em bens e serviços capazes de mitigar a ineficiência econômica (DRUCKER, 1969; PRAHALAD, 2006).

Essas ineficiências derivam de assimetria de informação, custos de transação elevados, concorrência imperfeita, mercados incompletos e a ausência de regulação (DUNDAS; RICHARDSON, 1980; SHANE; VENKATARAMAN, 2000; BARNEY et al, 2011). Quando expostas podem ser as oportunidades identificadas por pessoas que apresentam determinado perfil. Caso decidam explorá-las, elas se tornarão empreendedoras (SHANE; VENKATARAMAN, 2000).

O empreendedor precisa balancear riscos, informações assimétricas e lidar com restrições para reunir os recursos necessários para aproveitar a oportunidade de negócio (CASSON, 2005; BARON; SHANE, 2006). Isso envolve muito mais improviso e abertura a mudanças do que a relação estabelecida por incumbentes 
com suas rotinas estabelecidas, hierarquias e toda rigidez vinculada (LEONARD-BARTON, 1992). Talvez, por isso, suprir o déficit de acesso a alguns bens e serviços seja mais viável a partir de iniciativas que emergem do próprio território, do que sensibilizando empresas já estabelecidas (KARNANI, 2007).

O empreendedorismo é democrático, sendo muito mais uma questão de atitude, disposição e habilidade do que algo atribuído a fatores que limitam a entrada no mercado de trabalho regular, como escolaridade, apresentação e comportamento (SHANE; VENKATARAMAN, 2000; BARON; SHANE, 2006).

\section{A reaplicação do Projeto de Empreendedorismo}

A experiência aqui apresentada foi realizada no período novembro de 2016, por meio da identificação do perfil empreendedor, no intuito de colaborar com o incentivo ao empreendedorismo e a criação de renda a partir do seu próprio território. Nos territórios atendidos, o trabalho com os beneficiários - indivíduos e famílias - por meio das oficinas de empreendedorismo, visava preencher uma lacuna institucional, redesenhando olhares, práticas e a organização de recursos, transformando-os em oportunidades latentes (BARON; SHANE, 2006; SHANE, 2012; SHANE; VENKATARAMAN, 2000). Através do estímulo da construção de conhecimento (NONAKA; TAKEUCHI, 2008), os potenciais individuais e coletivos, sobretudo no trabalho em âmbito familiar, geraram novos impulsos produtivos com consequente potencial de maior circulação de renda no território.

A família era elegível ao projeto caso tivesse como membro um adolescente acompanhado pelo Serviço de Convivência e Fortalecimento de Vínculos do CRAS ou CREAS. Tanto o treinamento quanto a competição de melhor modelo de negócio eram realizados em família. O intuito da iniciativa era converter o rótulo do "jovem-problemático" para "jovem-potência", integrando o núcleo familiar em um ciclo virtuoso à medida que juntos construíssem tanto o saber quanto o próprio modelo de negócio. A referência familiar podia ser pai ou mãe, avó ou avô, tio ou tia, irmão mais velho, etc. Isso aumentou muito a heterogeneidade do grupo participante do projeto.

Toda metodologia do treinamento às batalhas de CANVAS - pitch - foram adaptadas da obra de Osterwalder (2011). O desafio residia, sobretudo, em possibilitar que todos os membros das famílias tivessem instrumentos básicos de elaboração em conjunto, a partir de um ciclo de estímulos capaz de fazê-los experimentar e aproveitar a experiência, e aprender fazendo; para que, com isso, aumentassem sua capacidade de realizar e concretizar ideias, além de utilizar essa nova base para se expressar no território (VELHO, 2013; LEFEBVRE, 2001). Como resultado, foi possível perceber que as famílias que participaram desse processo conseguiram mediar, articular desejos e necessidades ao seu campo de interesses, colocando seus melhores sentimentos numa arena virtuosa de cocriação, onde foi possível traçar objetivos temáticos transformados em modelos de negócios viáveis dentro de suas realidades (BARON; SHANE, 2006; OSTERWALDER, 2011).

\section{Metodologia}

Adota-se o paradigma positivista para a realização desta pesquisa quantitativa, na busca por generalizações com a pretensão de melhor compreender um fenômeno complexo de ciências sociais. A unidade de pesquisa adotada é o beneficiário das políticas públicas de assistência social que possuem vínculo estabelecido com algum CRAS ou CREAS. Combinou-se a literatura de empreendedorismo com a discussão de construtos que permeiam à ciência social. A pesquisa é descritiva quanto aos seus objetivos, pois busca caracterizar o perfil empreendedor, inferindo a relação do indivíduo com o seu território (MANGIONE, 1995; GIL, 2008).

A técnica de coleta de dados empregada foi Survey, método que promove o distanciamento do pesquisador em relação ao pesquisado, protegendo a interpretação da influência pessoal (GIL, 2008). O questionário aplicado foi desenvolvido para análise semelhante, aplicado em estudo do perfil empreendedor dos moradores do Programa Minha Casa, Minha Vida no Rio de Janeiro.

O questionário foi estruturado com base em duas fontes. Primeiro, nas seguintes questões propostas com 
base na literatura de empreendedorismo: 1) você pode lidar com incertezas?; 2) você tem disposição?; 3) você acredita em si e em suas capacidades?; 4) você pode lidar com contratempos e falhas?; 5) você tem paixão por seus objetivos?; 6) você é bom para outras pessoas (Responsabilidade) ?; 7) você é adaptável?; 8) você está disposto a assumir riscos? (BARON e SHANE, 2006; p.30).

Essas questões foram combinadas com os indicadores da pesquisa Adult Population Survey [APS]do GEM, um dos maiores repositórios de dados sobre empreendedorismo no mundo. A APS começou em $2001 \mathrm{e}$ ocorre anualmente, consultando pessoas entre 18 e 64 anos, em 60 países (http://www.gemconsortium.org/ consultado em, 12/04/2017).

As variáveis independentes selecionadas para explicar a variável dependente "Perfil Empreendedor" foram: 1) Capacidade de Identificar e aproveitar oportunidades; 2) Responsabilidade; 3) Delegação de tarefas; 4) Capacidade de previsão; 5) Tolerância aos riscos; 6) Grau de aversão à mudança; 7) Capacidade de aprendizado; 8) Inovação; 9) Motivação - Empreendedorismo por necessidade; 10) Motivação Empreendedorismo por oportunidade. Essas variáveis foram coletadas por meio de questões diretas, com respostas escalonadas com peso de 1 a 5, seguindo a Escala de Likert, com as variações: "Discordo totalmente" à "Concordo totalmente". A escala de Likert trata-se de uma escala psicométrica que pretende registrar o nível de concordância ou discordância com uma declaração dada (DALMORO; VIEIRA, 2013).

Outras variáveis também foram consideradas: 11) Idade (em função da idade economicamente ativa $x$ maturidade); 12) Escolaridade, 13) Experiência profissional, 14) Experiência empreendedora; 15) Maturidade do negócio, 16) Quantidade de funcionários, 17) se recebe algum benefício social, avaliadas por meio de questões dicotômicas e policotômicas. As variáveis consideradas com base em dados secundários foram: 18) Índice de Desenvolvimento Humano do Bairro [IDH], 19) Renda per capta do bairro, 20) Nível de emprego.

O raciocínio indutivo precisa da observação de uma realidade concreta e representativa do fenômeno, onde constatações particulares levam a inferências sobre o comportamento da população (GIL, 2008). Para tanto, foram aplicados 293 questionários, considerando amostragem probabilística, isto é, quando todos os membros da população têm a chance de serem selecionados, o que nos ajuda a aumentar a capacidade de generalização das conclusões encontradas (MANGIONE, 1995).

Logo, entre todas as famílias atendidas nos CRAS e nos CREAS algumas pessoas que acessaram esses serviços na data de aplicação dos questionários se voluntariaram a participar. A Tabela 1 demonstra como a amostra foi construída.

\begin{tabular}{|c|c|c|c|}
\hline Amostra & População & Amostra Sugerida & Amostra Obtida \\
\hline $4^{\text {a }}$ CDS - CRAS Nelson Mandela - 101 famílias & 101 & 39 & 62 \\
\hline $4^{\text {a }}$ CDS - CRAS Ramos - 53 famílias & 53 & 20 & 28 \\
\hline $8^{\text {a }}$ CDS - CRAS Olímpia Esteves - 65 famílias & 65 & 25 & 54 \\
\hline $8^{\mathrm{a}}$ CDS - CRAS Vila Moreti- 77 famílias & 77 & 30 & 60 \\
\hline $8^{a}$ CDS - CRAS Maria Thereza - 32 famílias & 32 & 12 & 24 \\
\hline $4^{\mathrm{a}}$ CDS - CREAS Nelson Carneiro - 182 famílias & 182 & 70 & 62 \\
\hline $4^{\mathrm{a}}$ CDS - CREAS Stella Maris - 40 famílias & 40 & 15 & 33 \\
\hline
\end{tabular}




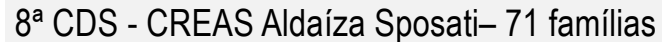

Total

$5 \%$ de Margem de Erro, intervalo de confiança de 95\%
71

621
Em 22/09/2016

27

238
47

370

Tabela 1: Amostragem.

Para quantificação dos resultados utilizou-se a análise multivariada por meio do software Statistical Package for Social Sciences [SPSS], empregando as técnicas de Regressão Linear e Análise de Cluster.

A primeira análise foi reaplicar a Regressão Linear do primeiro estudo para verificar a relevância das suas conclusões. Essa técnica permite identificar quais variáveis explicam o comportamento do perfil empreendedor e o quanto elas ajudam a predizê-lo (BELFIORE et al, 2009).

A análise de conglomerado foi aplicada para verificar se havia variáveis que ajudassem a caracterizar e separar por similaridade os indivíduos entrevistados (BELFIORE et al, 2009). Sua aplicação visou verificar se havia graus diferentes de perfil empreendedor de modo a formar pelo menos dois grupos distintos, um com mais e outro com menos perfil empreendedor. A importância dessa análise está na aplicação do modelo para um melhor direcionador do investimento dessas políticas públicas.

\section{Análise dos Resultados}

\section{Caracterização comparativa dos beneficiários de Políticas de Assistência Social}

O público estudado em ambos os casos acessa em maior ou menor escala os serviços de assistência social, porém, não se encontra em situações de extrema vulnerabilidade social, mantendo residência fixa, algum tipo de vínculo familiar e acessando seus direitos por meio do SUAS. $49 \%$ do público entrevistado recebe algum benefício social. Desses 157 indivíduos, 55\% possuem até 18 anos e 30\% mais de 55 anos, ambas as faixas naturais de recebimento de auxílio. Mais da metade do público entrevistado, em ambas as amostras, é feminino.

A maior diferença dos dois públicos é em relação a faixa etária: mais da metade dos entrevistados da SMDS são jovens (abaixo de 29 anos), ao passo que o público da primeira pesquisa é predominantemente maduro (acima de 36). Em tese, essa diferença de faixa etária influenciaria a escolaridade e a experiência profissional. 0 público deste segundo estudo realmente apresenta menor experiência $(39 \%$ nunca trabalhou), porém, a escolaridade de ambas as amostras é baixa, refletindo o grave problema da educação no Brasil (ALABARCE, 2015). A informalização do trabalho é proporcional em ambas às amostras, ademais a diferença de idade. A Figura 1 apresenta graficamente estas relações. A presença de indivíduos com experiência empreendedora prévia é proporcional em ambos as pesquisas (10\% na SMDS, 15\% MCMV).

Analisando a amostra da SMDS, embora haja representantes de todas as faixas etárias, infelizmente, a escolaridade desses empreendedores é baixa (ensino fundamental). Apenas 7 dos 30 empreendedores da amostra da SMDS já tiveram alguma experiência profissional. Isso pode configurar um reflexo das dificuldades enfrentadas pelas camadas mais baixas da sociedade em termos de acesso à educação e oportunidades no mercado de trabalho.

É curioso notar que 6 dos 13 empreendedores com até 18 anos já tiveram alguma experiência profissional, possivelmente um reflexo das necessidades sociais provenientes da condição de vulnerabilidade financeira das famílias. Metades desses empreendedores são jovens, o que pode significar que eles encaram 0 empreendedorismo como uma alternativa para superar a limitação de oportunidades no mercado de trabalho. 


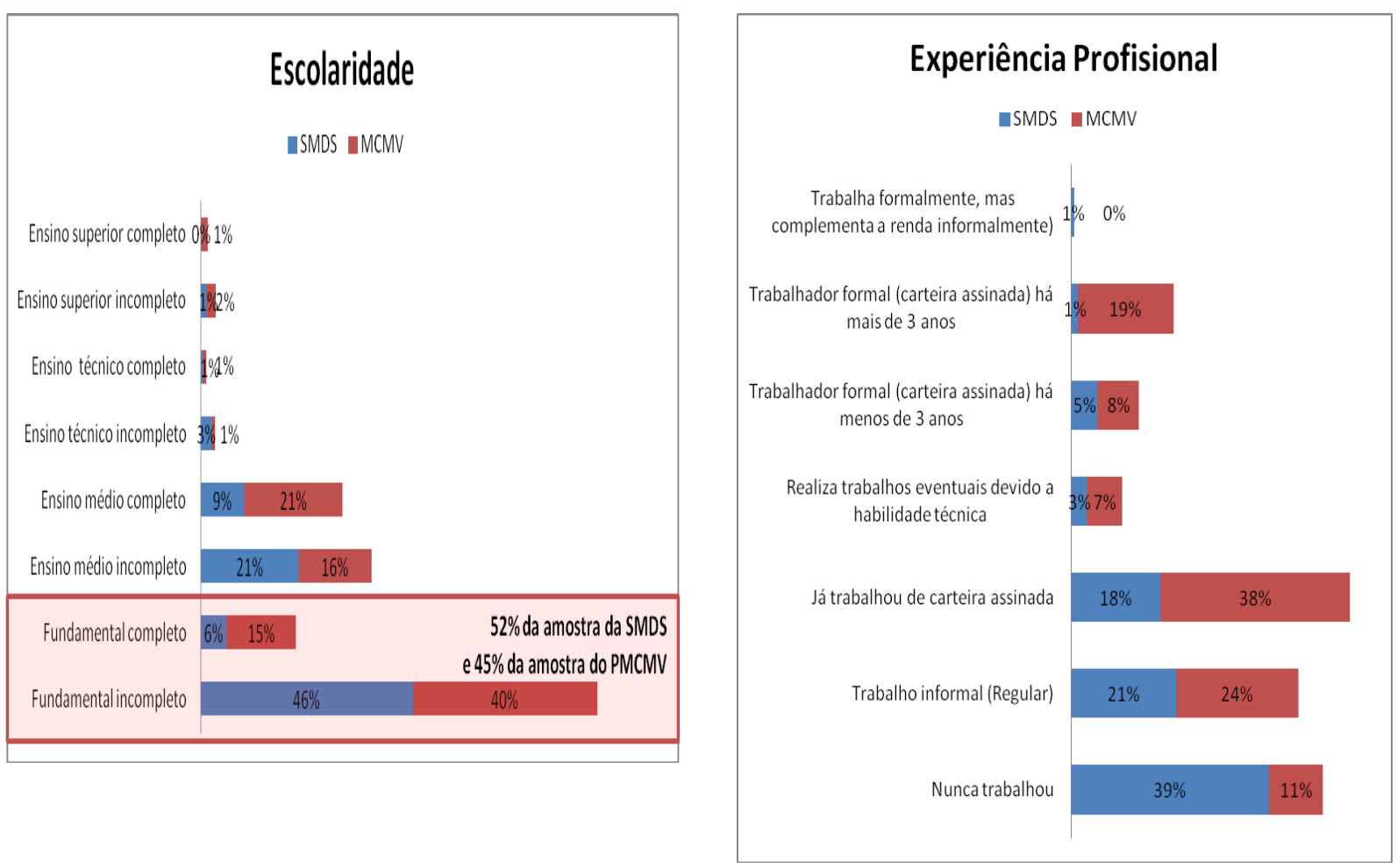

Figura 1: Escolaridade como barreira ao mercado de trabalho.

180 intenções de negócio foram sinalizadas nos questionários, sendo que $83 \%$ são relacionadas a alguma habilidade pessoal, o que pode indicar trabalho autônomo. A Figura 2 apresenta a consolidação dessas intenções de negócio.

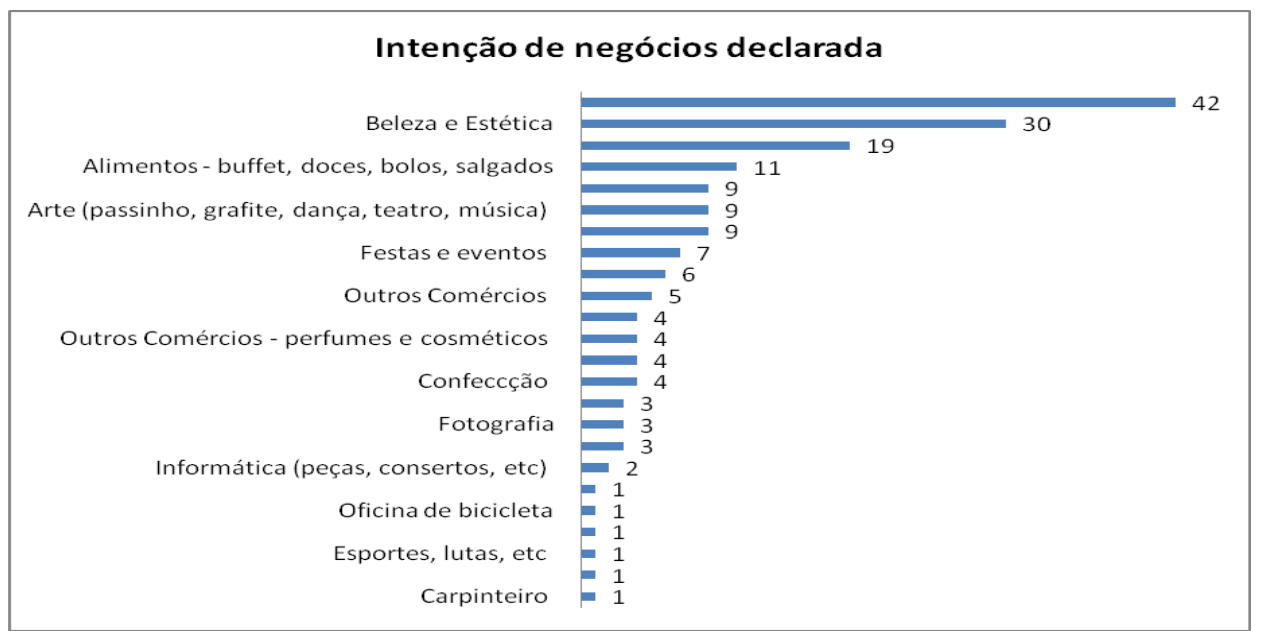

Figura 2: Intenção declarada de negócios.

\section{Análise dos dados}

Todos os pressupostos da regressão linear multivariada foram obedecidos, a saber: 1) a variável dependente é o resultado da função linear de suas regressões; 2) as estimadoras não estão enviesadas já que o termo de erro (u) é igual a zero; 3) os erros não estão correlacionados e possuem variação constante; 4) o número de observações é maior do que o número de casos e não há problema de multicolinearidade entre as variáveis. Apenas o pressuposto que exige que os coeficientes assumam o mesmo valor em amostras 
diferentes foi violado (BELFIORE et al, 2009).

A Tabela 2 demonstra a variação de coeficientes nos dois modelos, esses coeficientes demonstram o peso da variável na composição do perfil. Para verificar a natureza dessa variação foi reaplicada a estatística F, comparando a aplicação da equação do modelo nas duas amostras, segundo o teste de Chow, próprio para comparação de dois modelos de regressão linear (BELFIORE et al, 2009). A estatística $F(0,00403)$ foi menor que o $\mathrm{F}$ crítico $(0,6042)$, logo, os coeficientes das duas regressões são equivalentes, considerando a variância em cada amostra.

\begin{tabular}{|c|c|}
\hline Equação do modelo no $1^{\circ}$ estudo & Equação do modelo no $2^{\circ}$ estudo \\
\hline $\begin{array}{l}\text { perfil emp MCMV }=0,167+0,152 \text { identificar e } \\
\text { aproveitar oportunidades }+0,215 \text { responsabilidade } \\
+0,136 \text { delegação de tarefa }+0,206 \text { capacidade } \\
\text { de previsão }+0,091 \text { capacidade de aprendizado. }\end{array}$ & $\begin{array}{l}\text { perfil emp SMDS }=4,053+0,234 \text { identificar e } \\
\text { aproveitar oportunidades }+0,226 \text { responsabilidade } \\
+0 \text { delegação de tarefa }+0,473 \text { capacidade de } \\
\text { previsão }+0,696 \text { capacidade de aprendizado. }\end{array}$ \\
\hline
\end{tabular}

Tabela 2: coeficientes lineares nos dois modelos.

No estudo inicial a variação [R2] de perfil empreendedor era explicada $95,6 \%$ pela equação do modelo. Neste estudo, a mesma equação explica $84,10 \%$, porém, a variável "Delegação de tarefas" não se mostrou significativa, segundo a estatística T, sendo excluída do modelo. Com isso, houve perda de informações e o coeficiente de determinação caiu para $80,4 \%$. O resultado ainda é bastante significativo, o que demonstra a confiabilidade do modelo, principalmente por que os mesmos pressupostos foram atendidos. A Tabela 3 compara os dois modelos em relação às suas principais características

\begin{tabular}{|l|l|l|}
\hline Análises & Amostra SMDS & Amostra MCMV \\
\hline $\begin{array}{l}\text { Coeficiente de determinação ( } R^{2} \text { ajustado, para comparação } \\
\text { entre 2 amostras) o quanto o modelo explica a variação nas } \\
\text { diferentes amostras. }\end{array}$ & $80,1 \%$ & $96 \%$ \\
\hline $\begin{array}{l}\text { Erro utilizando a equação do modelo para predizer o perfil } \\
\text { empreendedor (Resíduos do modelo - SQR) }\end{array}$ & 48,847 & 0,006 \\
\hline Erro caso utilizasse a média dos casos para predição & 249,105 & 0,166 \\
\hline $\begin{array}{l}\text { Teste de Durbin-Watson com coeficiente próximo a 2 (dois) indica } \\
\text { ausência de auto correlação serial entre os resíduos, o que } \\
\text { reforça que as variáveis explicativas de fato influenciam a variável } \\
\text { dependente. }\end{array}$ & 1,867 & 2,207 \\
\hline Perfil médio aplicando a equação do modelo & 0,076 & 0,718 \\
\hline
\end{tabular}

Tabela 3: comparação estatística dos dois modelos

O teste "F" foi utilizado para verificar a significância do modelo, constatando se há relação de variação correlacionada entre variável dependente e as independentes. A soma dos quadrados dos resíduos demonstra que $80,52 \%$ de erro foi evitado pela utilização do modelo ao invés de uma simples média dos casos. Ainda analisando a qualidade do modelo, foi verificado se as variáveis independentes selecionadas estariam explicando a mesma informação. As variáveis inseridas no modelo apresentam uma multicolinearidade aceitável $(1<\mathrm{VIF}<10)$. Embora as medidas apresentem alguma correlação, não são 
recíprocas, logo, adicionam informação explicativa ao modelo ao invés de repeti-la (BELFIORE et al, 2009).

\begin{tabular}{|c|c|c|c|c|c|c|c|}
\hline \multirow[b]{2}{*}{ Modelo } & \multicolumn{2}{|c|}{$\begin{array}{l}\text { Coeficientes não } \\
\text { padronizados }\end{array}$} & \multirow{2}{*}{\begin{tabular}{|c|}
$\begin{array}{c}\text { Coeficientes } \\
\text { padronizados }\end{array}$ \\
Beta
\end{tabular}} & \multirow[t]{2}{*}{$t$} & \multirow[t]{2}{*}{ Sig. } & \multicolumn{2}{|c|}{$\begin{array}{l}\text { Estatísticas de } \\
\text { colinearidade }\end{array}$} \\
\hline & B & Erro Padrão & & & & Tolerância & VIF \\
\hline 1 (Constante) & 4,053 &, 029 & & 138,830 &, 000 & & \\
\hline $\begin{array}{l}\text { Identificar e aproveitar } \\
\text { oportunidades }\end{array}$ & ,234 & ,033 & ,188 & 7,060 & ,000 & ,878 & 1,139 \\
\hline Responsabilidade & ,226 & ,030 & 195 & 7,666 & 000 & ,964 & 1,038 \\
\hline Capacidade de previsão & ,473 & ,031 & ,402 & 15,304 & 000 & ,903 & 1,107 \\
\hline Capacidade de aprendizado & 696 &, 035 &, 543 & 20,013 &, 000 &, 847 & 1,181 \\
\hline
\end{tabular}

a. Variável Dependente: perfil empreendedor

Tabela 4: coeficientes e estatística T

A Tabela 5 testa o último pressuposto de avaliação do modelo: a normalidade dos resíduos por meio do teste Kolmogorov-Smirnov [KMO]. Este pressuposto foi validado para todas as variáveis $(a>0,05)$.

Aplicando a equação do modelo em cada caso, notamos índices maiores e menores. A análise de conglomerado buscou analisar se os casos podiam ser divididos em grupos e se esses grupos permitiam inferir algo sobre a população (BELFIORE et al, 2009). Essa análise apontou para a existência de dois grupos. Um predominante que abarcava 302 casos com maior perfil empreendedor e um com os 17 casos de menor perfil. Essa análise não foi possível com a amostra do primeiro estudo. Sua importância é sinalizar que nem todos os casos são de perfil empreendedor. Seu resultado está alinhado com a literatura. Shane e Venkataraman (2000) onde estimam que o número de pessoas que possuem características aderentes ao perfil empreendedor varia de 20 a 50 por cento da população mundial.

\section{Conclusão}

A primeira hipótese $(\mathrm{H} 1)$ deste estudo se confirma devido ao alto poder explicativo da equação do modelo linear aplicado as duas amostras distintas, porém, representativas da população atendida pelo sistema de assistência social no município do Rio de Janeiro. A análise de cluster ajudou a evidenciar que a grande maioria dos casos $(94,67 \%)$ apresentam esse perfil.

Se por um lado é ótimo saber que o investimento tem potencial de ser aproveitado devido a esse alto perfil, por outro isso dificulta a utilização dessa informação como um critério para predizer o sucesso da ação empreendedora ou o resultado de políticas de incentivo ao empreendedorismo (SHANE; VENKATARAMAN (2000).

Cabe ressaltar que projetos de estímulo podem ser um grande incentivo para que perfis empreendedores avancem mais um passo, assumindo uma atitude empreendedora, tirando suas ideias do papel. Aproveitar o potencial latente para que esse torne-se uma ação potente, pode ser a chave desse tipo de iniciativa, assumindo, inclusive, que muitas pessoas não irão aderir à proposta ou que muitos negócios acabem não logrando êxito (HAYWARD et al, 2006). A experiência já consolidada no âmbito do programa Minha Casa, Minha Vida demonstrou que em apenas seis meses, após a conclusão das entregas dos prêmios, $59 \%$ das 
famílias tinham como principal receita a proveniente dos negócios incentivados. No âmbito da SMDS não houve tempo suficiente para mensurar o êxito da ação concreta que viabilizou este estudo comparativo.

Como um dos objetivos do SUAS (BRASIL, 2005) é promover a autonomia, essa expectativa é aderente a concretização da política pública, buscando desenvolver mecanismos de emancipação por meio da geração de renda a partir das capacidades individuais, das oportunidades e necessidades do território.

Novamente, as características que historicamente dificultam o acesso ao mercado de trabalho escolaridade e experiência profissional -, não se mostraram estatisticamente relevantes para 0 desenvolvimento de atividade empreendedora, confirmando a segunda hipótese (H2). Esse achado reforça o potencial do empreendedorismo ser um indutor da construção de autonomia e lança a questão sobre 0 papel da educação na formação do cidadão brasileiro. Mais uma vez, concluímos que características como a capacidade de aprendizado, planejamento (previsão), dentre outras, devem ser conjugadas ao treinamento e mentoria, enquanto caminho possível no desenvolvimento de habilidades para 0 empreendedorismo local.

A experiência tem maior papel na aquisição de conhecimento para essa classe social do que a possibilidade viabilizada pelo direito público à educação. Desse modo, o conhecimento é adquirido nos seus múltiplos percursos, marcados pela convivência contraditória, mais ou menos diferenciada, entre negociação e choque, com a principal injunção imposta por uma sociedade educada a partir de padrões e acessos desiguais (SOUSA, 2009; ALABARCE, 2015; SOARES, 2017). Esse argumento se sustenta a partir da formulação de Paulo Freire (1996, p. 21): "Ensinar não é transferir conhecimento, mas criar as possibilidades para a sua produção ou a sua construção".

Dito de outra forma, a política de assistência social deve transmitir o conhecimento e acesso suficientemente capaz de proporcionar ao seu beneficiário a compreensão do contexto em que se insere e, a partir daí, permitir, apoiar e desenvolver em cocriação com esse beneficiário um novo sentido, criando um campo de possibilidades que restaure a esperança dos indivíduos em relação ao seu futuro. 0 exercício da autonomia e conquista da emancipação social, política e financeira, passam pelo acesso ao conhecimento e pela gestão de oportunidades, haja vista que o déficit educacional não justifica a tutela do indivíduo. A mitigação do seu efeito deve ser pensada.

Isso reforça a necessidade de políticas emergenciais de reparação e transição. Da mesma maneira que 0 desejo deveria ser pelo trabalho e não pelo emprego, ou seja, no lugar da educação formal "propor" profissões, ela deve construir ambientes para o desenvolvimento de habilidades para a criatividade, para 0 empreendedorismo, para os indivíduos serem o que quiserem (SOUZA, 2009; FREIRE, 1996).

Mais uma vez, os beneficiários, que em geral ocupam um lugar passivo no que tange o acesso aos benefícios sociais em função de sua vulnerabilidade, demonstraram um potencial de protagonismo. Essas pessoas demonstraram boa capacidade de previsão que requer planejamento e visão de futuro. Boa capacidade de adaptação, bom relacionamento com situações de mudanças e incertezas, características essenciais para sobrevivência de negócios (SOUZA; LOPEZ JR; 2005; CASSON, 2005; FILARDI et al,2014;).

Foi identificada uma grande capacidade de identificar e aproveitar oportunidades, algo essencial à prática empreendedora (BARON; SHANE, 2006; SHANE; VENKATARAMAN, 2000) e contraditória em relação ao baixo aproveitamento das ações sociais. Uma grande queixa do investimento social é seu baixo retorno em autonomia, caindo em geral, em uma situação paternalista. Porém, para identificar e aproveitar oportunidades, é necessária autonomia, que, em conjunto com a variável responsabilidade, mostra o quanto o fenômeno da má fé institucional é perverso (SOUZA, 2009). A adequação da oferta à real demanda dessas pessoas, permitindo sua participação ativa poderá gerar bons frutos para além da expectativa de geração de emprego e renda (SUMMER, 2015). Há ganhos de autoestima, de sentimento de pertencimento e diversos outros potenciais anguladores de conduta que permitirão o rompimento de ciclos e a construção 
de trajetórias mais positivas (DUHIGG, 2012).

Em suma o modelo permite mensurar que a cada variação de 1 ponto percentual de capacidade de identificar e aproveitar oportunidades afeta em 0,234 o perfil empreendedor. Cada ponto percentual de aumento de responsabilidade, o perfil empreendedor aumenta 0,226 . Cada ponto percentual de aumento de capacidade de previsão, o perfil empreendedor aumenta 0,473 e para cada ponto percentual de aumento de capacidade de aprendizado, o perfil empreendedor aumenta 0,696. Essas estatísticas podem colaborar com a tomada de decisão e servir como balizadores de investimentos públicos em ações que promovam o aprimoramento dessas características.

O tipo de motivação empreendedora não apresentou relevância para esse público, o que pode sinalizar a necessidade de revisão de algumas correlações propostas pelo GEM em relação ao que motiva o empreendedorismo por necessidade e os efeitos do ecossistema empreendedor nesse tipo de motivação. Algumas características muito centradas na divisão entre países desenvolvidos e subdesenvolvidos que sustentam o argumento do GEM não puderam ser comprovados por meio dessa amostra, onde IDH e Renda per capta, por exemplo, não se mostraram relevantes (LEVIE; AUTIO, 2008; HERRINGTON; KEW, 2016). Este artigo também agrega informação empírica que reforça elementos do perfil empreendedor proposto por Baron e Shane (2006), um dos muitos estudos que busca elencar essas características.

A sua relevância prática está na caracterização do perfil empreendedor desse público especifico, que em geral não é acessado por estudos de empreendedorismo. Ele agrega a intersetorialidade entre a administração e o campo da assistência social. A equação proposta ambiciona descrever um fenômeno complexo por meio da sua racionalização matemática, não para simplificá-lo e limitá-lo a um modelo, mas para fomentar mais reflexões sobre os elementos que o compõem. Assim, almeja-se municiar o tomador de decisão de mais informações para o fomento do empreendedorismo local e alocação de investimentos sociais.

Os autores são gratos por terem participado da construção do modelo e da metodologia aplicada à execução de ambas as iniciativas, no programa Minha Casa, Minha Vida e na SMDS. Como sugestão de estudos futuros fica a ampliação qualitativa da compreensão desse fenômeno, acompanhando os resultados de ambas as iniciativas. Seria interessante a análise dos resultados atuais dos negócios desenvolvidos para verificar o seu impacto na vida dos participantes e no território.

A reaplicação do modelo em outras amostras para comparação dos resultados também seria relevante, principalmente por que a análise estatística empregada não permite classificar novos casos. Uma base de dados maior talvez permita atender aos pressupostos para geração de uma análise descriminante (BELFIORE et al, 2009). A comparação dos resultados da pesquisa de perfil empreendedor com outras pesquisas e bases de dados poderia refinar o modelo proposto, tornando-o mais robusto e replicável.

Esta pesquisa buscou evidenciar aspectos do perfil empreendedor da classe popular carioca para gerar reflexão e sinalizar a importância da implementação das políticas de elevação da inclusão, da redução dos níveis de desigualdade e pobreza. Espera-se, com isso, fomentar o debate, apresentando dados e fatos para favorecer o desenvolvimento da administração pública da cidade do Rio de Janeiro. 0 empreendedorismo pode ser uma alternativa válida para ajudar a superar limitações decorrentes da desigualdade social, desenvolvendo autonomia e gerando emprego e renda a partir do território.

\section{Referências}

ALABARCE, M. C. Regímenes de Bienestar en América Latina y el Caribe: notas para pensar lo contemporáneo. Trabajo Social Global. Revista de Investigaciones en Intervención Social, v. 5, n. 8, p. 26-46, 2015

BARON, Robert; SHANE, Scott. Empreendedorismo: uma visão do processo; São Paulo: Cengage Learning, 2007. 
BELFIORE, Patricia; PRADOCHAN, Betty; FAVERO, Luiz Paulo Lopes; SILVA, Fabiana Lopes da. Analise de dados - modelagem multivariada para tomada de decisões. São Paulo: Campus. 2009.

BRASIL. Ministério do Desenvolvimento Social e Combate à Fome. Caderno de Estudos do Curso em Conceitos e Instrumentos para o Monitoramento de Programas. Brasília: MDS, Secretaria Nacional de Assistência Social, 2014.

BRASIL. Ministério do Desenvolvimento Social e Combate à Fome. CapacitaSuas: Caderno 2. Proteção de Assistência Social, segurança de acesso a benefícios e serviços de qualidade. Brasília: MDS, 2013

BRASIL. Ministério do Desenvolvimento Social e Combate à Fome. Política Nacional de Assistência Social e Norma Operacional Básica do SUAS. Brasília: MDS, 2005.

CASSON, M. Entrepreneurship and the theory of the firm. Journal of Economic Behavior and Organization, 58(2), 327-348, 2005. Disponível em: http://doi.org/10.1016/j.jebo.2004.05.007

CHIAVENATO, Idalberto. Princípios da Administração: o essencial em Teoria Geral da Administração. São Paulo: Manole Ltda, 2013.

CHOWDHURY, S. R., Wealth inequality entrepreneurship and industrialization. Journal of Economics, v. 108, n.1, p.81-102, 2013.

DACIN, P. A; DACIN, M. T.; MATEAR, M. Social Entrepreneurship: Why We Don't Need a New Theory and How We Move Forward From Here; Academy of Management Perspectives, 2010

DALMORO, Marlon; VIEIRA, Kelmara mendes. Dilemas na construção de escalas tipo likert: o número de itens e a disposição influenciam nos resultados? Rgo Revista Gestão Organizacional, vol. 6 - edição especial, 2013

DUHIGG, Charles. 0 Poder do Hábito: Por Que Fazemos o Que Fazemos na Vida e Nos Negócios. Editora Objetiva, 2012

DRUCKER, Peter. The age of discontinuity: Guidelines to our changing society; Nova York; Harper and Row; 1969

FILLARDI, L. F; BARROS, F. D; FISCHMAN, A. A. Do home empreendedor ao empreendedor contemporâneo: Evolução das características empreendedoras de 1948 a 2014. Revista lberoAmericana de Estratégia. 2014. e-ISSN: 2176-0756.

FREIRE, Paulo. Pedagogia da Autonomia - Saberes necessários à prática educativa. São Paulo, Editora Paz e Terra, 1996

GIL, Antônio Carlos. Métodos e técnicas de pesquisa social. São Paulo: Atlas, 6a edição. 2008.

HAYWARD, M. L. A., SHEPHERD, D. A., GRIFFIN, D., CROMIE, S., \& CALLAGHAN, A. Hubris Theory of Entrepreneurship. Management Science, 4(2), 65-71, 2006.

HERRINGTON, Mike; KEW, Penny. Global Report 2016/2017. GEM - Global Entrepreneurship Monitor, 1180, 2016.

KARNANI, A. G. Fortune at the Bottom of the Pyramid: A Mirage. Working Papers (Faculty) -- University of Michigan Business School, (1035), 1-1, 2007.

LEFEBVRE, Henri. 0 direito à cidade. Trad. Rubens Eduardo Frias. São Paulo, Centauro, 2001.

LEONARD-BARTON, Dororthy. Core Capabilities and Core Rigidities: A Paradox in Managing New Product Development. Strategic Management Journal, Vol. 13, Special Issue: Strategy Process: Managing Corporate Self-Renewal; p. 111-125; 1992 
LEVIE, J; AUTIO, E. A theoretical grounding and test of the GEM model. Small Business Economics, 31(3), 235-263, 2008.

MANGIONE, Thomas W. Mail Surveys: Improving the Quality. SAGE Publications, Inc. Vol. 40. JSI Research and Training Institute, Boston, 1995.

NONAKA, I.; TAKEUCHI, H. Gestão do Conhecimento. Rio de Janeiro; editora Bookman, 2008.

OSTERWALDER, Alexander. Inovação Em Modelos de Negócios - Business Model Generation; Alta Books, 2011.

PRAHALAD, C. K. (2006). A Riqueza Na Base Da Piramide. C. K. Prahalad E Stuart L. Hart, 391, 2006.

PIKETTY, Thomas. A Economia da Desigualdade. Traduzido por André Telles. Editora Intrínseca, 2015

SANTANA, Vagner C. Pobreza, exclusão social e territorialidades. V Congresso em Desenvolvimento Social, 2016.

SEBRAE - Serviço Brasileiro de Apoio a Micro e Pequena Empresa. Taxa de sobrevivência das empresas no Brasil. Pesquisa disponível em: https://www.sebrae.com.br/sites/PortalSebrae/estudos_pesquisas/taxade-sobrevivencia-das-empresas-no-brasildestaque15,01e9f925817b3410VgnVCM2000003c74010aRCRD consultado em 19/06/2017.

SHANE, S. Reflections on the 2010 AMR Decade Award: Delivering on the Promise of Entrepreneurship as a Field of Research. Academy of Management Review, 37(1), 10-20, 2012.

SHANE, S; VENKATARAMAN, S. The promise of entrepreneurship as a field of research. Academy of Management Review, 25(1), 217-226, 2000.

STIGLITZ, Joseph E. El precio de la desigualdad. Diario El País, 2012. Disponível em:

http://economia.elpais.com/economia/2012/06/15/actualidad/1339754056_983920.html

SOARES, Laura Tavares Ribeiro. América Latina: Modernização ou Retrocesso Social?. CLACSO, 2017

SOUZA, E. C. L.; LOPEZ JR., G. S. "Atitude empreendedora em proprietários-gerentes de pequenas empresas. Construção de um instrumento de medida - IMAE. Anais do Encontro Nacional da Associação Nacional de Pós-Graduação e Pesquisa em Administração, Brasília, DF, Brasil, 2005.

SOUZA, Jesse. Ralé Brasileira - quem é e como vive. Belo Horizonte; Editora UFMG, 2009.

SUMMERS, D. (2015). The Economic Impact of Entrepreneurship. Academy of Entrepreneurship Journal, 21(2), 99-108, 2015. Disponível em: https://doi.org/10.1007/978-1-4419-1191-9

VELHO, Gilberto. Um antropólogo na cidade: ensaios de antropologia urbana. Rio de Janeiro: Zahar, 2013. 